Case Report

\title{
New Insights about Pulmonary Epithelioid Hemangioendothelioma: Review of the Literature and Two Case Reports
}

\author{
Romeu Duarte Mesquita, ${ }^{1}$ Marta Sousa, ${ }^{1}$ Carmen Trinidad, \\ Eugénia Pinto, ${ }^{3}$ and Iosu Antón Badiola ${ }^{4}$ \\ ${ }^{1}$ Department of Radiology, Centro Hospitalar de Entre o Douro e Vouga, Santa Maria da Feira, Portugal \\ ${ }^{2}$ Department of Radiology, Hospital Povisa, Vigo, Spain \\ ${ }^{3}$ Department of Pathology, Centro Hospitalar de Lisboa Central, Lisboa, Portugal \\ ${ }^{4}$ Department of Pathology, Hospital Povisa, Vigo, Spain
}

Correspondence should be addressed to Romeu Duarte Mesquita; romeu.mesquita@gmail.com

Received 10 April 2017; Accepted 4 July 2017; Published 14 August 2017

Academic Editor: Suayib Yalcin

Copyright (C) 2017 Romeu Duarte Mesquita et al. This is an open access article distributed under the Creative Commons Attribution License, which permits unrestricted use, distribution, and reproduction in any medium, provided the original work is properly cited.

Pulmonary epithelioid hemangioendothelioma $(\mathrm{PEH})$ is a rare neoplasm of vascular origin. There are three different major imaging patterns identified in thoracic manifestation of epithelioid hemangioendothelioma: (1) multiple pulmonary nodules; (2) multiple pulmonary reticulonodular opacities; and (3) diffuse infiltrative pleural thickening. Radiographically, presence of bilateral multiple nodules is the most common pattern of presentation. The diagnosis is made on the basis of histopathological findings and confirmed by positive immunohistochemistry staining. Although the prognostic factors for PEH have not yet been well established, a better prognosis is usually associated with the multinodular pattern. We report two different imagological presentations of this rare disease, based on two institutional experiences, along with a review of the relevant literature.

\section{Introduction}

Pulmonary epithelioid hemangioendothelioma $(\mathrm{PEH})$ is a rare neoplasm of vascular origin. It is a low-to-intermediate grade malignant tumor, of borderline malignancy and a clinical course usually between hemangioma and angiosarcoma. Unfortunately, there is no clear definition of malignant $\mathrm{PEH}$. The term "epithelioid hemangioendothelioma" was first introduced by Weiss et al. as a soft tissue vascular tumor of borderline malignancy [1].

However, the lesion was originally described in 1975 by Dail et al. as an "intravascular bronchoalveolar tumor," initially believed to be an aggressive form of the bronchoalveolar cell carcinoma [2].

Epithelioid hemangioendothelioma $(\mathrm{EH})$ is classified as a vascular tumor because the neoplastic cells have characteristics in common with normal, nonneoplastic endothelial cells [3]. EH can behave in a locally aggressive fashion, with metastases being rare [4].

Corrin et al., using immunohistochemical techniques, demonstrated the presence of malignant cells deriving from a lineage capable of differentiation along endothelial lines [5]. Subsequently, Weldon-Linne et al., using electron microscopy, confirmed these results and revealed diffuse cytoplasmic staining of the tumor cells with a factor VIIIrelated antigen [6].

Histologic characteristics of $\mathrm{EH}$ include epithelioid cells with abundant eosinophilic cytoplasm in a fibromyxoid stroma, some of them with intracytoplasmic vacuoles, having a signet ring-like appearance. These features can, however, be also found in primary adenocarcinoma, mesothelioma, and large-cell lymphoma, so immunohistochemical analyses, especially those for the endothelial markers, are a mainstay [7-10]. 


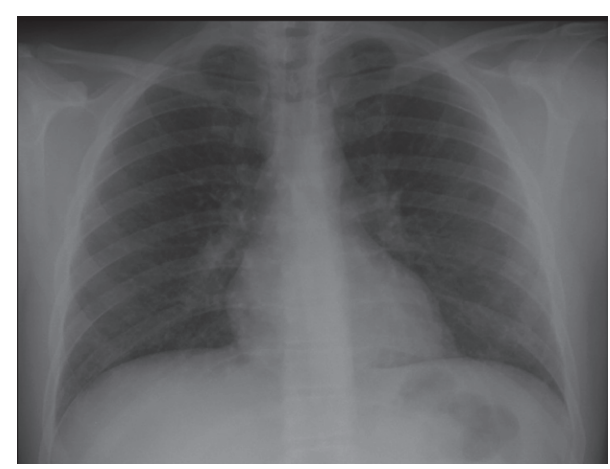

(a)

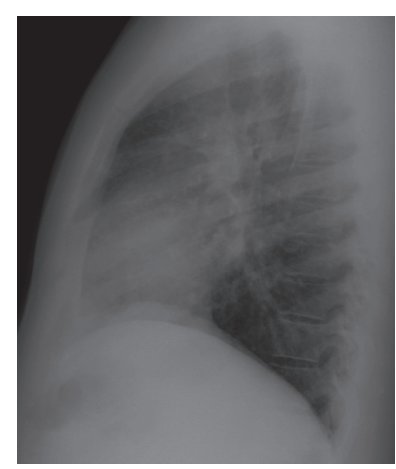

(b)

FIGURE 1: Posteroanterior (a) and lateral (b) chest X-rays. The chest radiography showed a diffuse nodular pulmonary pattern in both lungs.

The 2015 WHO Classification of Tumors of the Lung, Pleura, Thymus and Heart [11] recently published, with numerous important changes from the 2004 WHO classification, has a significant change involving recognition of usefulness of WWTR1-CAMTA1 fusions in diagnosis of pulmonary EH. The new information regarding this tumor is recognition of a translocation involving the WWTR1 and CAMTA1 genes and prognostic factors [12].

This update was based on the recent recognition that a recurrent $\mathrm{t}(1 ; 3)(\mathrm{p} 36.3 ; \mathrm{q} 25)$ chromosomal translocation is characteristic of EH. Additionally, the genes involved in the EH translocation were identified, namely, WWTR1 (or TAZ) and CAMTA1, resulting in a transcription factor, WWTR1CAMTA1 fusion protein. Also significant is the lack of CAMTA1 and WWTR1 rearrangements in epithelioid hemangioma, a benign vascular tumor that can be misdiagnosed as EH [13-17].

Tanas et al. [18] suggest that the WWTR1/CAMTA1 gene fusion plays a pivot role in the tumor biology and can act as a transcription factor that ultimately may represent a therapeutic target for EH-specific drugs. Recently, Antonescu et al. $[19,20]$ report a novel subset of EH occurring in a specific group of young adults, where they found a distinct phenotype with YAP1-TFE3 fusions but similar morphologic features. Although further studies [21] confirm these results others question the utility of immunohistochemical YAP1TFE3 fusion detection [7, 14].

Another hypothesis for the pathogenesis of this neoplasm, reported in the literature, mentions a possible causal relationship between chronic Bartonella infection and the development of this rare vascular tumor in immunocompetent patients [22].

Some authors also believe in a hormonal potential significance in this disease because the greater incidence is observed in women; also, hormone receptor expression has been reported in the literature $[23,24]$ and a recent case report describes recurrence of $\mathrm{EH}$ during pregnancy [25].

All these data highlight the current emerging development about the knowledge concerning biochemical and clinical behaviour of EH in general and $\mathrm{PEH}$ in particular and can lead to greater understanding of the molecular pathways in the tumor and great advances in potential therapies.

$\mathrm{EH}$ remains, however, a little-understood disease and one of the main reasons for that is the fact that the prevalence of $\mathrm{EH}$ is reported to be less than one in 1 million [26].

\section{Case 1}

A 35-year-old male, nonsmoker, without symptoms and with no prior history of lung diseases had a routine chest radiograph that showed alterations. His past medical history was not significant, without occupational exposures or family history of clinical relevance. The physical examination was unremarkable. Chest X-ray demonstrated the presence of a diffuse and bilateral micronodular infiltrate (Figure 1).

Serum levels of neoplastic markers and angiotensin converting enzyme were within normal values. The pulmonary function tests were also in the normal range. The bronchoscopy performed with bronchoalveolar lavage, brushing, and transbronchial biopsies were nondiagnostic. Chest high resolution (HR) computed tomography (CT) scan showed multiple, bilateral small pulmonary nodules (with diameters inferior to $10 \mathrm{~mm}$ ) (Figure 2).

These nodules were present in all pulmonary lobes and adjacent to bronchioles and medium/small vessels. There were no enlarged lymph nodes, pleural effusion, or other relevant pulmonary changes. Abdominal and pelvic CT revealed no malignant lesions (Figure 3 ).

Radiological skeletal study also showed no bone involvement. Surgical lung biopsy was performed and histological examination of the nodules revealed epithelioid cells with eosinophilic cytoplasm and intracytoplasmic vacuolization. On immunohistochemical studies, the tumor cells were immunoreactive to CD34 and negative for cytokeratin (Figure 4).

Because the progression was slow, follow-up was suggested. In agreement with his decision, close follow-up with chest CT was planned.

He still has no symptoms and has survived for 48 months following the initial diagnosis. 


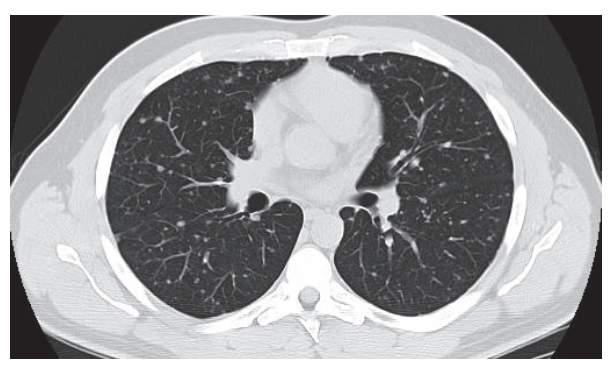

(a)

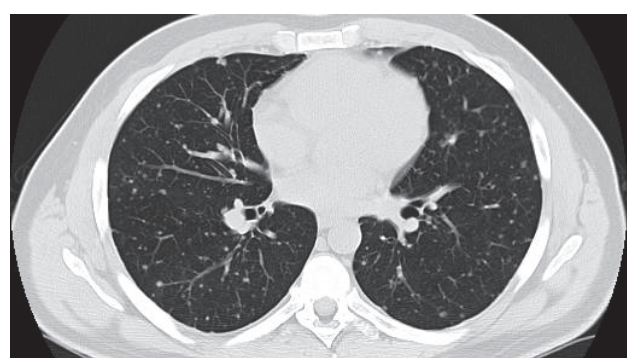

(b)

FIGURE 2: Chest CT ( $\mathrm{a}$ and b). Multislice chest CT-images on lung window showed innumerable, well-defined, small, round, and noncalcified pulmonary nodular opacities, scattered in both lungs. These nodules were present in all pulmonary lobes and adjacent to bronchioles and medium/small vessels.

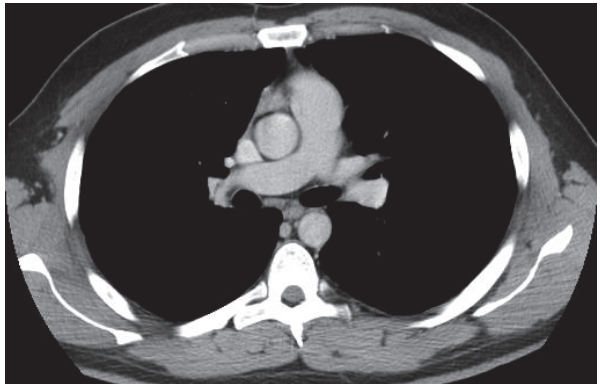

(a)

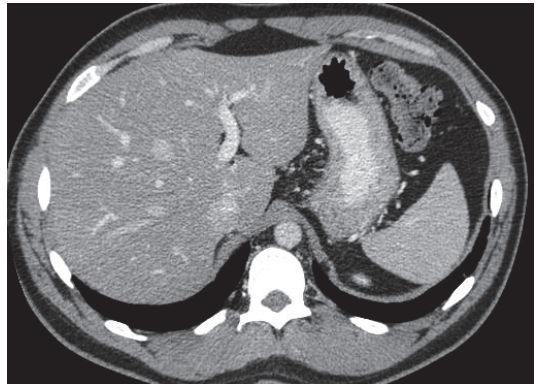

(b)

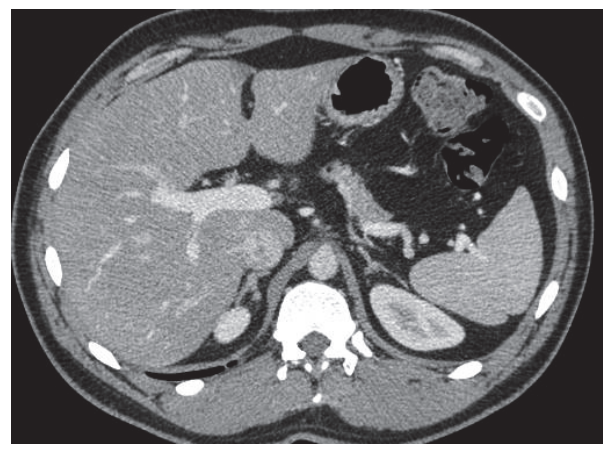

(c)

FIGURE 3: Contrast-enhanced multislice CT of the chest (a) on mediastinal window showed no thoracic lymphadenopathy. Multislice abdominopelvic CT scans (b and c) with intravenous contrast administration showed no significant findings, excluding focal liver or splenic lesions.

\section{Case 2}

A 67-year-old woman, nonsmoker, presented in the emergency department with a complaint of mild productive cough for 2 months with hematic sputum in the last 24 hours. She also reported progressive left-sided dorsal pain over 1month duration. Her past medical history revealed a previous diagnosis of deep vein thrombosis in 2012. In a routine chest radiograph made 2 years previously, it was hard to depict any pulmonary pathology (Figure 5).

Her family history was unremarkable. There were no other specific abnormalities on physical examination. The laboratory findings were within normal range. Chest X-ray demonstrated the presence of a poorly defined opacity in the left lower lung and a blunt costophrenic angle in the left side (Figure 6).

Spirometry showed forced vital capacity (FVC) of 1.59 (69.1\%), forced expiratory volume in 1 second (FEV1) of 1.16 (60.7\%), FEV1/FVC of 76\%, and diffusing capacity divided by the alveolar volume (DLCO/VA) of 103.3\%. Extensive pulmonary workup for pulmonary nodules including bronchoscopy, bronchoalveolar lavage (BAL), and transbronchial lung biopsy was completed. Results were negative for infectious or rheumatologic processes. The transbronchial biopsy 


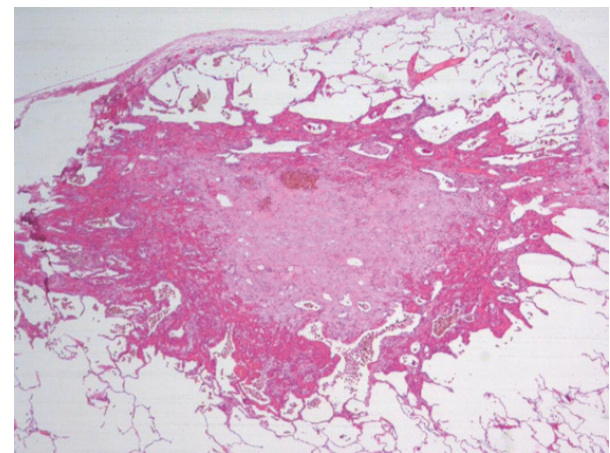

(a)

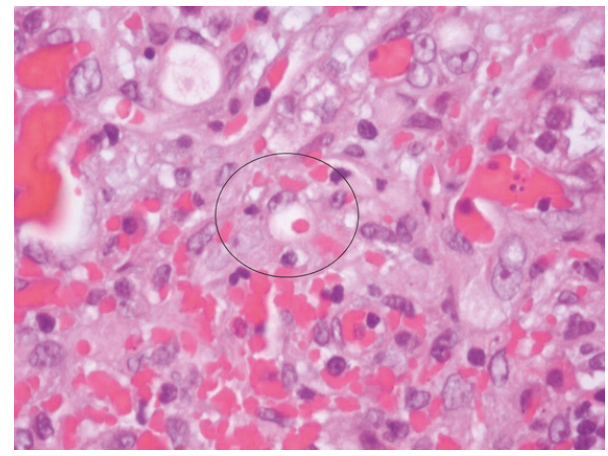

(c)

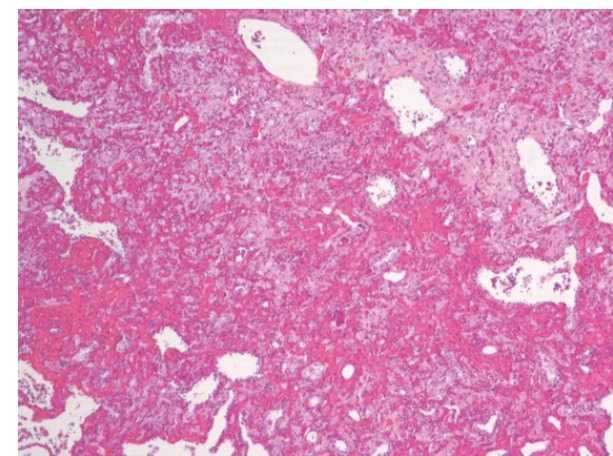

(b)

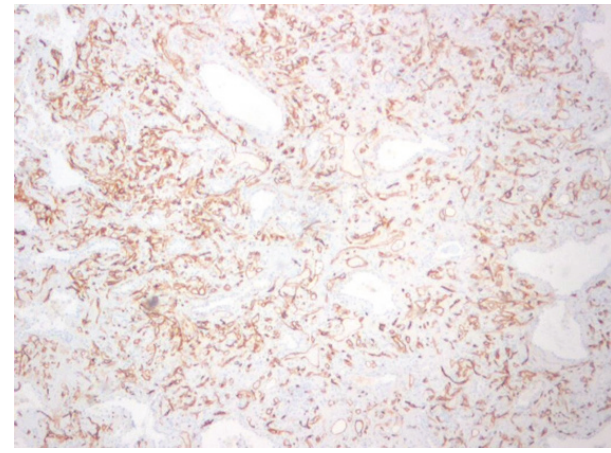

(d)

FIgURE 4: Histopathologic findings of hemangioendothelioma. (a) Low magnification of the specimen obtained from pulmonary wedge resection reveals a subpleural nodule that extends to adjacent alveoli, with vascular proliferation in the peripheral zone and areas of recent and old hemorrhage. (b) Neoplastic nodule showing tumor cells with an eosinophilic stroma at the periphery. The lesion contains blood filled spaces and respiratory epithelium "trapped" within the lesion is also shown. (c) Higher magnification of the tumor reveals vacuolation of some of the tumor cells, representing primitive angiogenesis. One of these epithelioid cells can be observed with intracytoplasmic lumen and an erythrocyte inside, indicating their vascular nature. (d) Immunostaining for CD34 revealed positivity of the neoplastic cells (brown colour), confirming the endothelial lineage of the tumor.

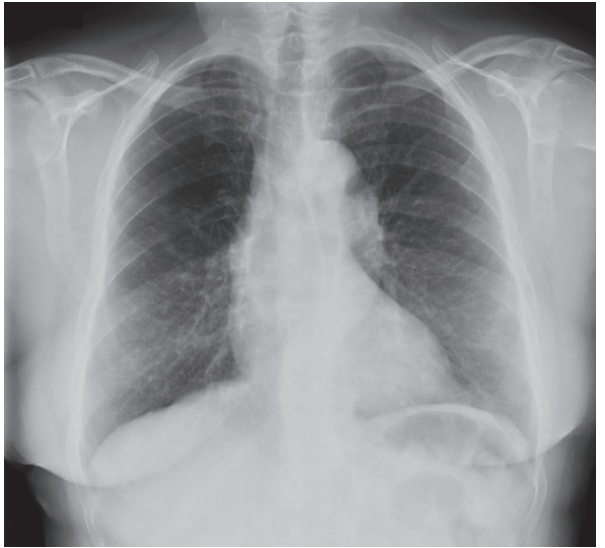

(a)

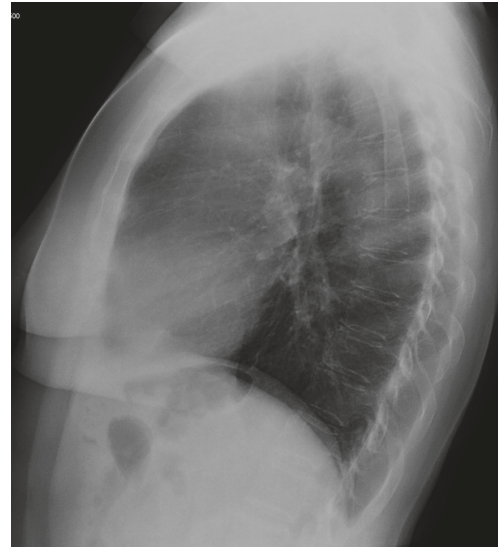

(b)

FIGURE 5: Posteroanterior (a) and lateral (b) chest X-rays. In a routine chest radiography 2 years before presentation in the ER it was difficult to detect the lesion in the left lower lung. 


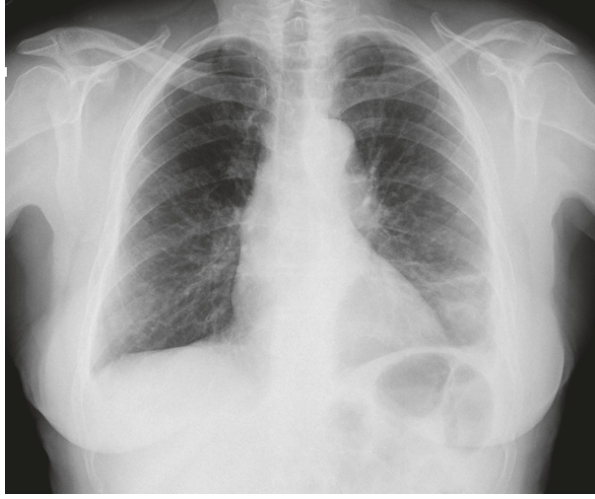

(a)

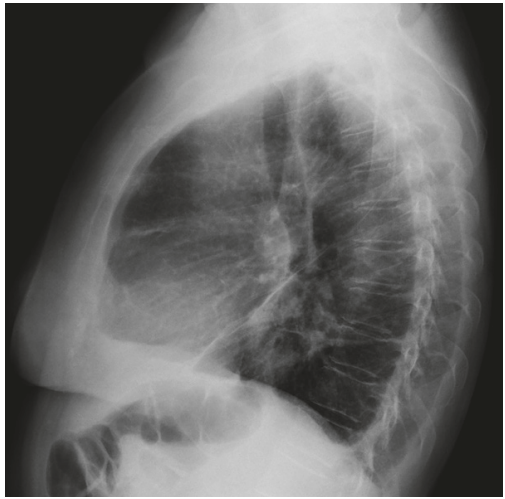

(b)

Figure 6: Posteroanterior (a) and lateral (b) chest X-rays. The chest radiography showed a peripheral lesion in the left lower lung and a small volume of pleural effusion on the same side.

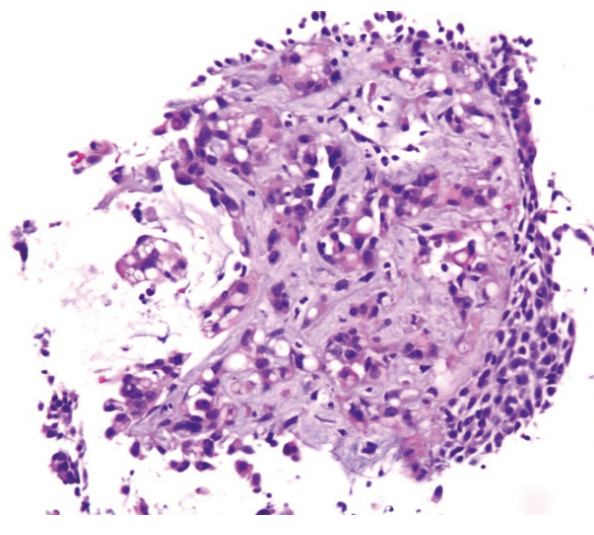

(a)

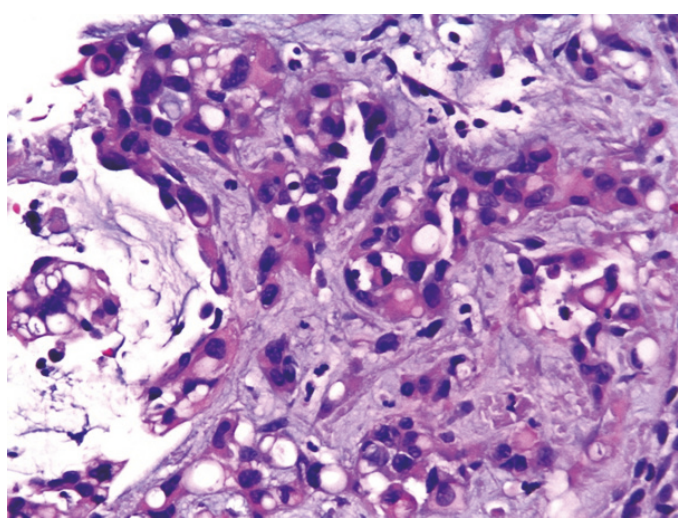

(b)

FIGURE 7: Transbronchial biopsy of a pulmonary mass (H-E). (a) 10x. (b) 20x. Vascular proliferation and endothelial cells, frequently with citoplasmatic vacuolization, in a fibromyxoid stroma, with bronchial surface epithelial lining.

showed atypical cellular infiltrate with immunohistochemical expression very suggestive of proliferative lesion of vascular origin (Figure 7).

A chest CT scan revealed the presence of a lung mass in the parenchyma of the left inferior lobe (LIL), with necrotic component and in contact with the parietal pleura and diaphragmatic pleura, with associated partial atelectasis of the same lobe and coexisting multiple nodules scattered in both lungs (Figure 8); a single hilar ipsilateral lymphadenopathy was identified and no mediastinal lymphadenopathy or significant pleural effusion were present at presentation.

Patient underwent a first chest CT-guided lung biopsy that revealed intense fibrosis and focal changes suggestive of proliferative vascular lesion. She repeated the lung biopsy that showed the presence of atypical epithelioid-like tumor cells (Figure 9). Immunohistochemical studies were positive for CD31, CD34, and factor VIII. These results were consistent with the diagnosis of $\mathrm{PEH}$.

She underwent a FDG PET/CT (not shown) that showed areas of increased uptake of FDG, including the pulmonary mass in the LIL as a hypermetabolic lesion and the left hilar lymphadenopathy. There was no abnormal FDG uptake in the small pulmonary nodules

One thoracic magnetic resonance (MR) with paramagnetic contrast, done two months later, demonstrated a left pleural effusion but did not show unequivocal abnormal pleural enhancement compatible with pleural metastases (Figure 10).

Three months later, under general anaesthesia, the surgeons performed a wedge resection by thoracotomy that also revealed multiple small pleural implants, both in visceral and in parietal pleural lesions, which were biopsied. Tumor specimens acquired showed pathological features of $\mathrm{EH}$.

After a scheduled oncology visit the patient began treatment with six cycles of chemotherapy with carboplatin/ paclitaxel, which changed to doxorubicin/cyclophosphamide.

Another chest CT, three months after the initial CT, showed rapid progression of the disease depicted by increase in number of the pulmonary nodules and the pleural lesions. 


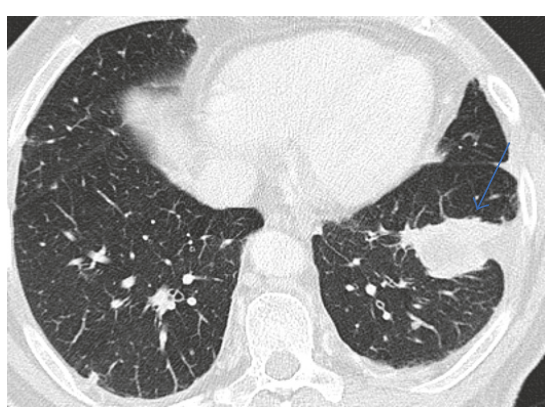

(a)

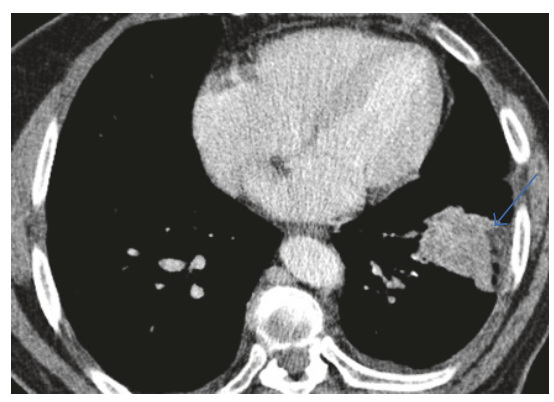

(d)

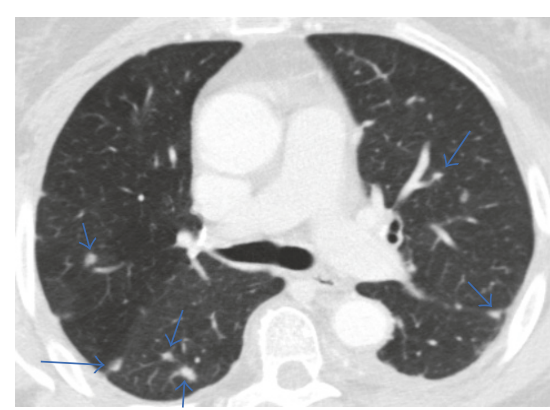

(b)

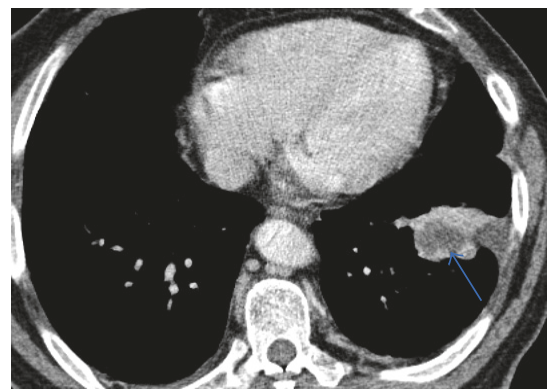

(e)

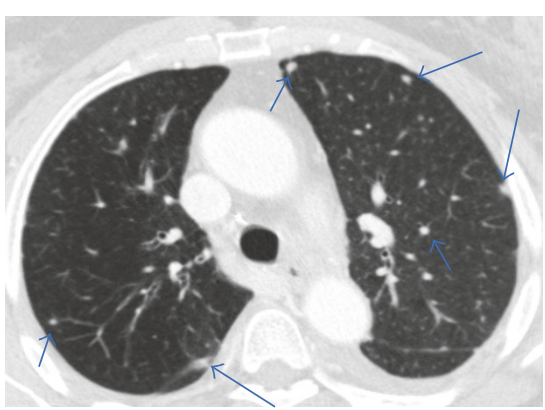

(c)

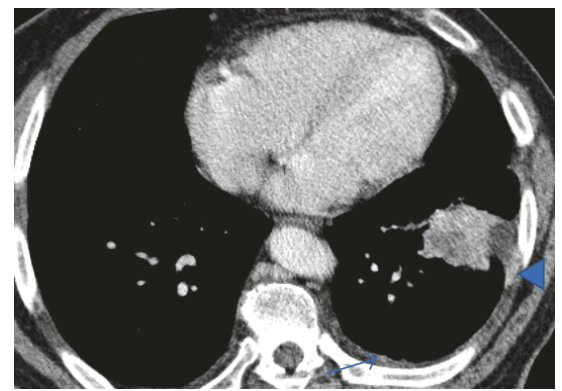

(f)

Figure 8: Chest CT. Multislice chest CT-images on lung window ( $a, b$, and c) showed a lung mass with irregular borders (a); they also showed multiple small, round, and noncalcified pulmonary nodular opacities, scattered in both lungs (b and c). On mediastinal window (d, e, and f) it is possible to better identify the pleural invasion (d) and the necrotic areas in lesion (e), retrospectively, and valorization is hard when the exam was performed, and we can recognize areas of enhancement in the left pleura, more nodular (arrow) or linear (arrowhead) (f).

Also, showing increment in diameter, the splenic nodular lesions were compatible with metastases (Figure 11).

The patient returned to emergency department, seven months after the first visit, with progressive dyspnea.

A chest CT made at this time showed advance disease with a new lesion appearing in the contralateral pulmonary parenchymal and growth of the primary lesion in the left lung, illustrating the aggressive behaviour of the disease. The pulmonary nodules, however, did not show significant increment in size despite the completely different evolution seen in the lesion of the lower left lung (Figure 12).

Unlike this, the spleen showed an increase in number and size of the nodular lesions in his parenchyma. Although we did not have pathologic confirmation, because the patient did not have any other primary neoplastic lesion, these features reinforce the probable diagnosis of metastases from the $\mathrm{PEH}$ (Figure 13).

Upon her readmission, 2 weeks later, the patient succumbed to her condition due to respiratory failure.

\section{Discussion}

Using the International Hemangioendothioma, Epithelioid Hemangioendothelioma, and Related Vascular Disorders (HEARD) Registry, an Internet database with data of 206 patients, Lau et al. [15] found that the most commonly affected organs were liver and lung, and single organ involvement occurred in more than $60 \%$ of patients. The most common presentations were liver alone (21\%), liver plus lung (18\%), lung alone (12\%), and bone alone (14\%).

There is still no characteristic clinical or biological marker for PEH. PEH typically occurs among young patients and is more common in women than in men and many patients are asymptomatic at presentation, so it is often an incidental finding on imaging studies. Other possible symptoms can be minor or nonspecific pulmonary symptoms, such as chest pain, effort dyspnea, cough, and sputum [8, 14, 26-32]. There are sporadic reported cases of atypical symptoms related to unusual clinical course and/or extraordinary aggressiveness [33].

The prognosis is very variable, with survival ranging from less than one year up to 30 years [34]. Slow progression or growth for long periods and spontaneous regression may occur, especially in asymptomatic patients [27]. According to Lau et al. analysis, the 5-year overall survival is 73\% [15]. The mortality for lung disease, with a minimum of follow-up of 4 years, was reported to be $65 \%$ [1].

The prognostic factors for $\mathrm{PEH}$ have not yet been well established. Pulmonary symptoms and, specially, pleural hemorrhagic effusions and hemoptysis are generally considered the worst prognostic factors [28]. Symptomatic patients and presence of pleural effusion were found to be independent predictors of survival. Other significant risk factors for $\mathrm{PEH}$ are male gender, presence of cough, chest pain, multiple unilateral nodules, metastases to more than one site, and lymph node metastases [26]. 


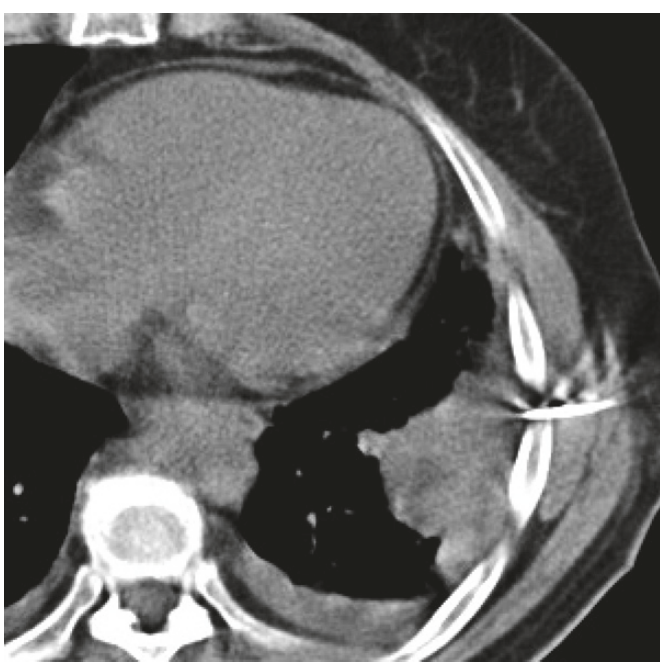

(a)

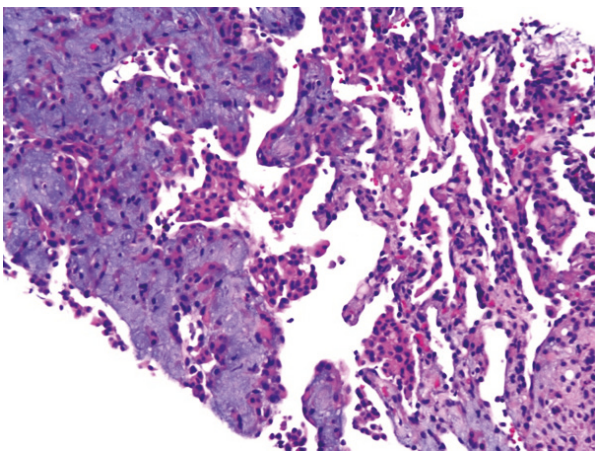

(c)

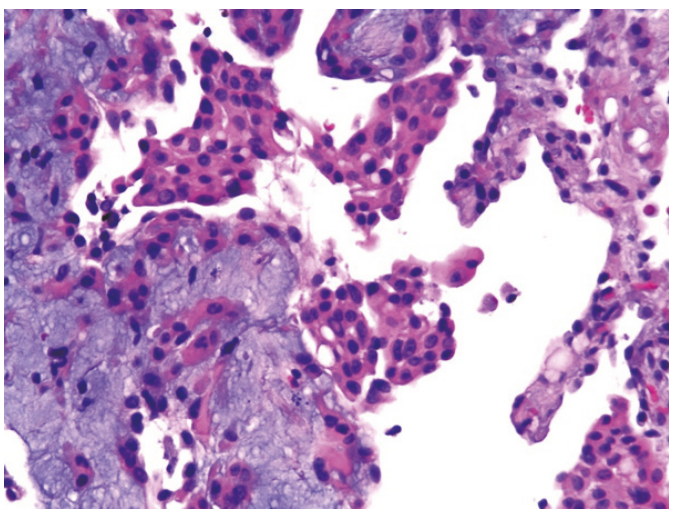

(e)

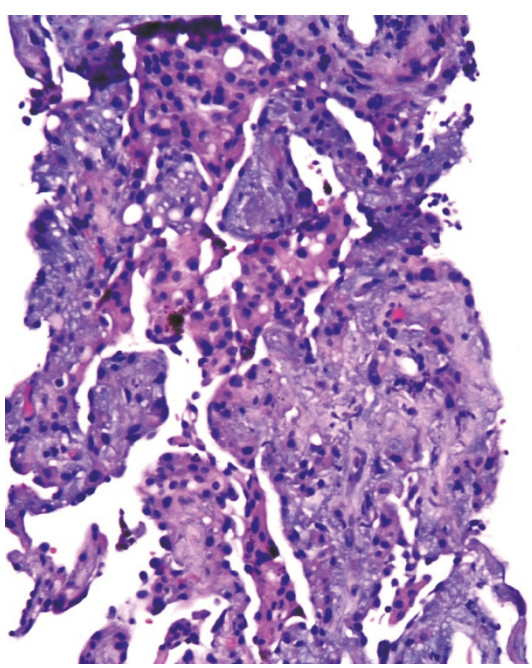

(b)

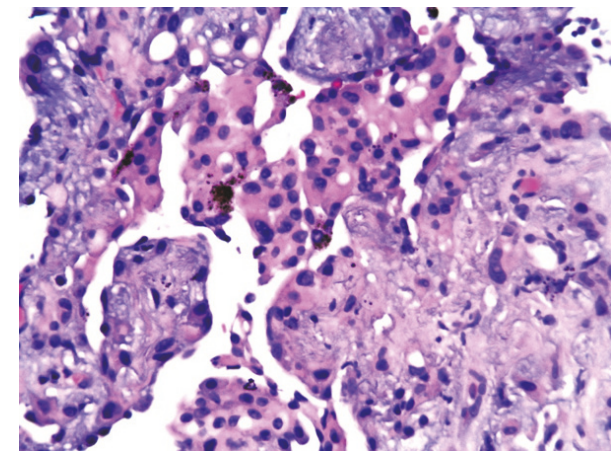

(d)

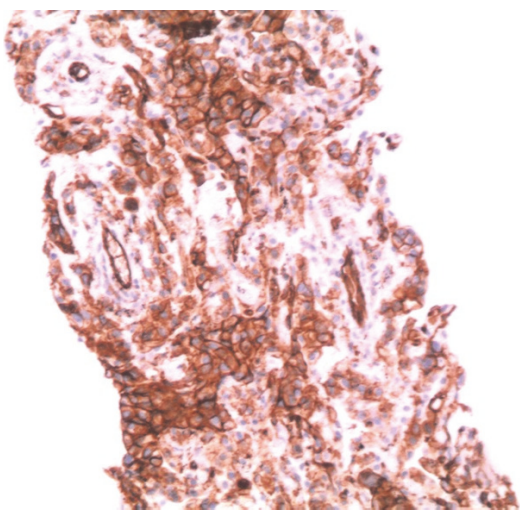

(f)

Figure 9: $20 \mathrm{G}$ Tru-Cut biopsy of the lung mass (a). H-E (b-e) images show vascular proliferation with epithelioid cells in a fibromyxoid stroma and presence of haemosiderophages $((\mathrm{b}, \mathrm{c}) 10 \mathrm{x}$; (d) 20x). Some of the epithelioid cells show vacuolation (e). Immunostaining for CD31 revealed positivity of the neoplastic cells (brown colour), confirming the endothelial lineage of the tumor.

Another study using cases from International HEARD Support Group found that although concurrent multiorgan involvement is common at the time of diagnosis, no specific organ or combination of organ involvement differentially affected survival, and there were no differences in patient's survival with single versus multiple organ involvement in their cohort [15]. They also confirmed that hemoptysis and pleural effusion or other signs of uncontained tumor growth have prognostic value and involve worse survival. These authors also categorized the patients into two different patterns of disease at presentation (A and $\mathrm{B}$ ) based on presence or absence of lesions with discrete/defined borders, with 


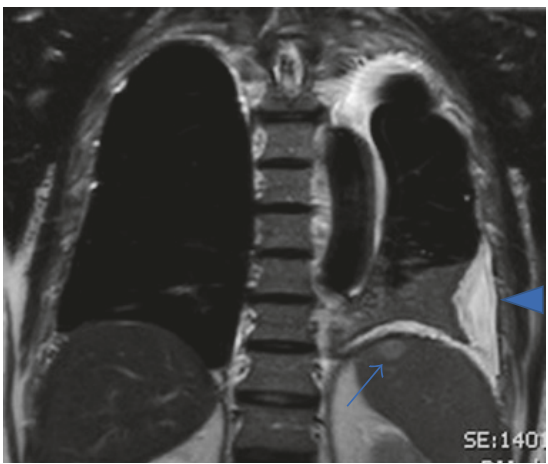

(a)

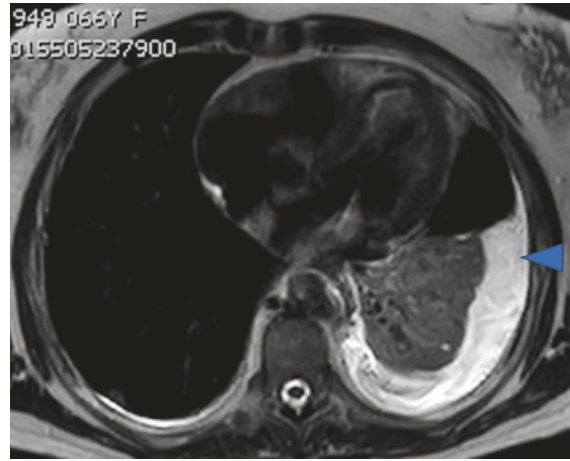

(b)

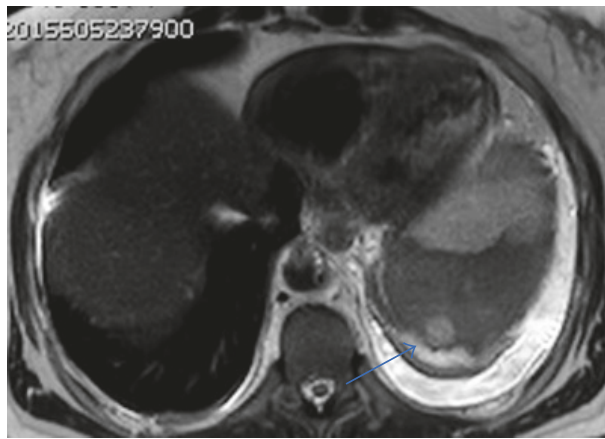

(c)

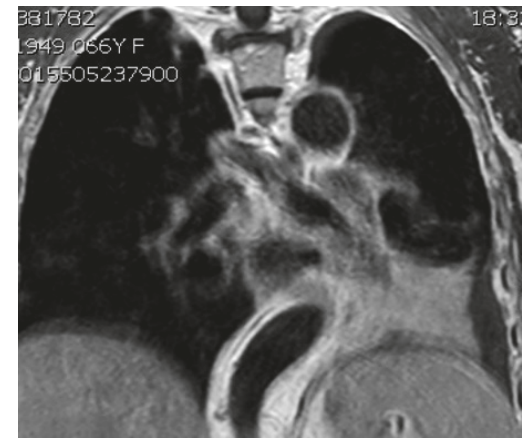

(d)

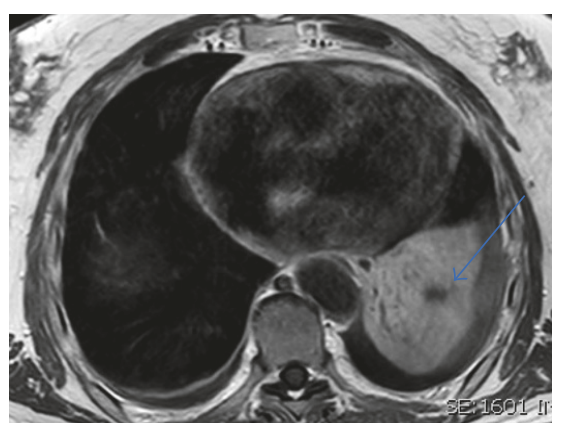

(e)

FIgURE 10: Thoracic MR images. Fluid sensitive sequences (a-c) show the presence of left pleural effusion (arrowhead) and also the nodular lesions in the spleen, which do not correspond to cysts (arrows). T1 weighted images with contrast ( $\mathrm{d}$ and e) show the pulmonary mass and hypodense zones representing necrotic areas (arrow).

pattern B in the chest including pulmonary infiltrates, pleural effusion, extrapulmonary thoracic disease, and the symptom of hemoptysis and found a strong predictive prognostic value.

In terms of clinical features, it seems that the prognosis of PHE reflects primarily the vascular aggressiveness markers of hemorrhagic symptoms.

Although there are controversies regarding the multicentric or metastatic nature of $\mathrm{EH}$, it can affect many organs simultaneously or sequentially, and lungs and liver are the two organs most frequently involved [15, 30,35]. Although $\mathrm{PEH}$ is capable of producing regional and distant metastases, the metastases occur less frequently than in conventional angiosarcoma [26].

Dissemination of PEH can occur through blood vessels and lymphatics and within the pleural cavity [36]. Although rare, when the primary location is the lungs, distant metastases to the liver, skin, kidney, spleen, and retroperitoneum can occur and have been reported in the literature $[2,27,28$, 37-41]. Weiss et al. [1] reported that metastatic disease occurs in approximately $15 \%$ of patients with lesions affecting the lung.

Although it is unclear if the expression of CD44 has a major role in PEH invasiveness and metastases (because the number of patients tested is limited) Yi et al. [42] suggested the potential of intravascular invasion in a patient presenting with pulmonary thromboembolic disease and pulmonary hypertension.
Nevertheless, in patients with also hepatic involvement, knowledge of the CT manifestations in the liver may be helpful to narrow the differential diagnoses.

$\mathrm{EH}$ in the thorax can involve not just the lungs but also the pleurae and the mediastinum $[14,31,43-45]$. There are three major different patterns of CT findings identified in thoracic manifestation of EH [46-48]: (1) multiple pulmonary nodules; (2) multiple pulmonary reticulonodular opacities; and (3) diffuse infiltrative pleural thickening.

Radiographically, bilateral multiple nodular nodules are the most common presentation [27, 49]. The presence of multiple discrete pulmonary perivascular nodules with wellor ill-defined margins in both lungs on chest radiographs or CT is the characteristic finding. The nodules can range in size up to $3 \mathrm{~cm}$, but most are less than $1 \mathrm{~cm}$ in diameter and are usually found in relation to small and mediumsized vessels and bronchi. This form of presentation may appear in many lung diseases and is easily mistaken for metastatic carcinoma, which is usually the initial radiologic interpretation [50]. However, little growth is shown on serial chest CT examinations $[8,50]$. When this pattern is found the differential diagnosis list generally includes the following: pulmonary metastases, miliary granulomatous infection, sarcoidosis, silicosis, primary lung malignancy, and lymphangitic carcinomatosis.

There is a trend toward better prognosis for the multinodular pattern and the largest studies/reviews that assess 


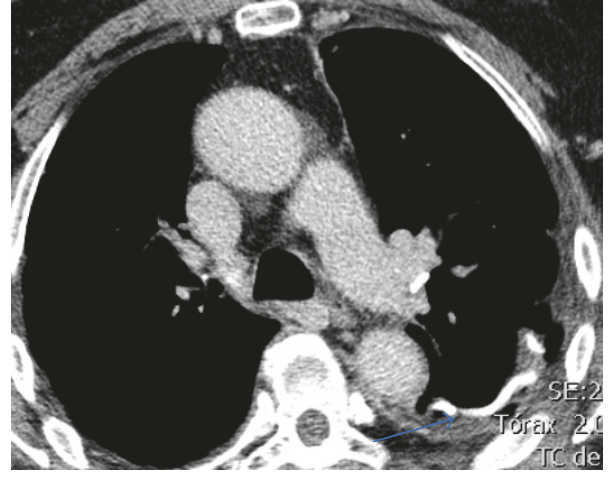

(a)

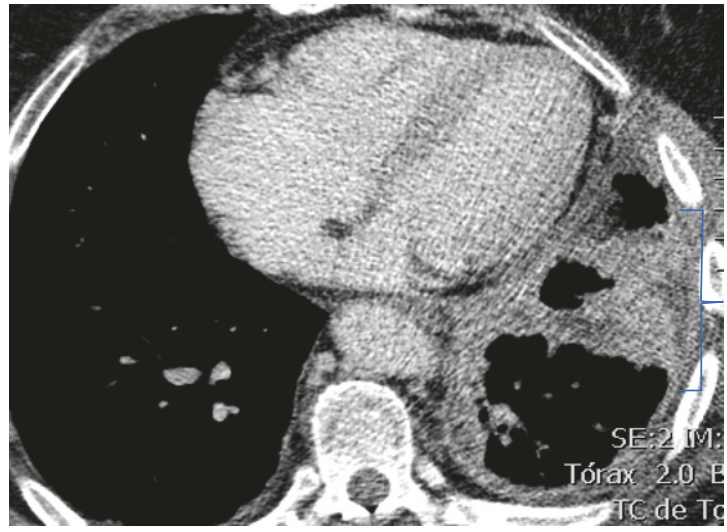

(c)

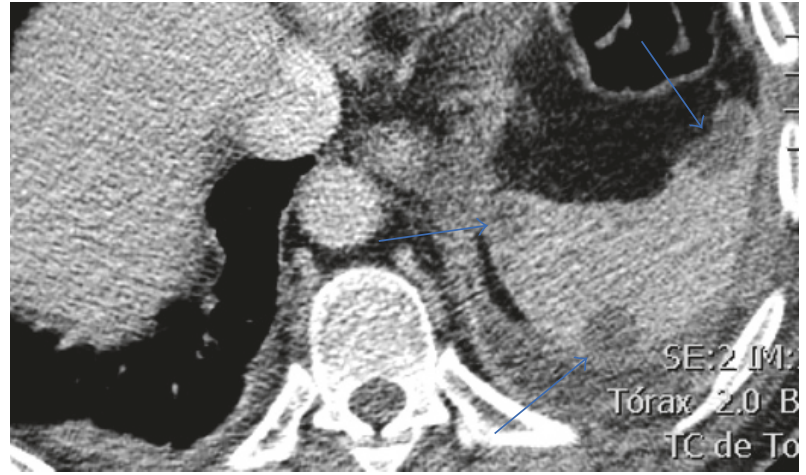

(b)

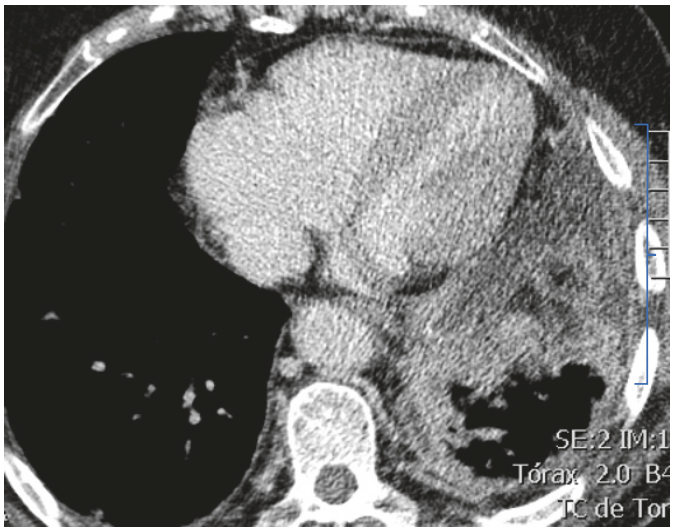

(d)

Figure 11: Chest CT. Multislice chest axial CT-images on mediastinal window show (a) signs of previous atypical wedge resection in the left lower lobe (arrow); (b) more nodular lesions in the spleen (arrows); (c and d) more pronounced and diffuse pleural invasion (brackets).

the relation between imaging features/different patterns and prognosis show that longer survival corresponds to the presence of multiple pulmonary nodules [26-28, 30, 32].

To the best of our knowledge, at least when the imaging pattern was specifically reported, all the cases that report complete/partial response or with spontaneous regression correspond to the multinodular pattern $[1,27,34,37,51-61]$

This issue is extremely important because, due to the heterogeneity of $\mathrm{PEH}$, the specific imaging pattern from radiologic diagnosis may be a pivot step in the approach of the patient with $\mathrm{PEH}$ and ultimately can define the option about the treatment. Furthermore, perhaps the results about treatment efficacy cannot be compared when the lesions do not have homogeneous patterns.

Particularly interesting is the fact already described in other tumors not so distinct from $\mathrm{PEH}$, like is the case of bronchioloalveolar carcinoma. In these tumors it is the clinical pattern and pathologic stage, and not the degree of invasion on histologic examination, that can predict survival [62].

Multiple pulmonary reticulonodular opacities represent, histopathologically, areas of infiltrating nodular proliferation of neoplastic cells within the lumina of small blood vessels and lymphatic vessels [26, 29, 47, 49]. In fact, in their study, Woo et al. [32] found a clinical significance in their similarity to pulmonary metastases in terms of prognosis, although just three patients had this pattern. This pattern may also suggest a more aggressive infiltrative growth into the lung interstitium, depicted histopathologically by infiltrative nodular proliferation of tumor cells within the vessel lumina $[63,64]$.

When the disease presents as diffuse infiltrative pleural thickening with associated pleural effusion, it can simulate malignant pleural mesothelioma or diffuse pleural carcinomatosis $[16,45,65,66]$.

An extra pattern can be added to the previous three identified ones, defined as parenchymal tumor with pleural invasion [32]. This pattern was previously described in some reports in the literature [27, 67-70] and Woo et al. described it in 4 patients. The major importance of this pattern relies on the fact that imaging features can greatly simulate the much more common primary non-small-cell lung tumor. Indeed, as was the case with all the four patients of Woo et al. study, also in one of our patients primary lung cancer with pleural seeding was the initial differential diagnosis.

Other unusual radiologic findings in sporadic cases are described in the literature, like irregular interstitial thickening and ground-glass opacities as the dominant feature, mimicking diffuse lung disease [63]. 


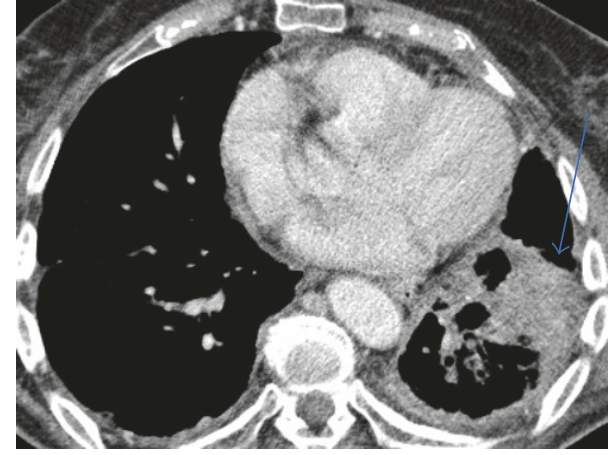

(a)

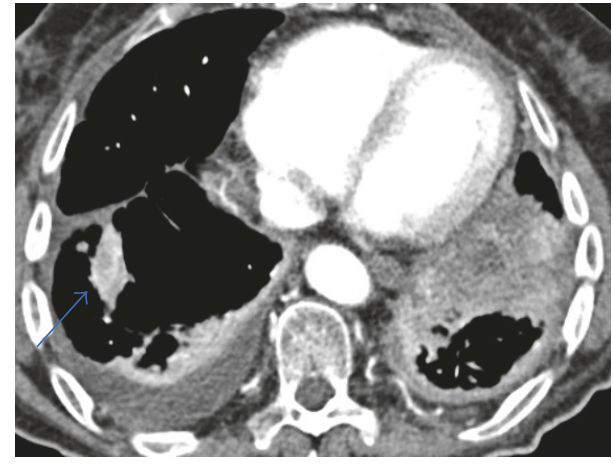

(c)

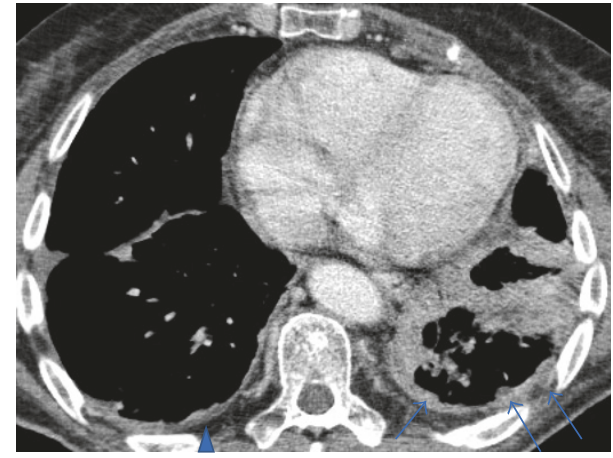

(b)

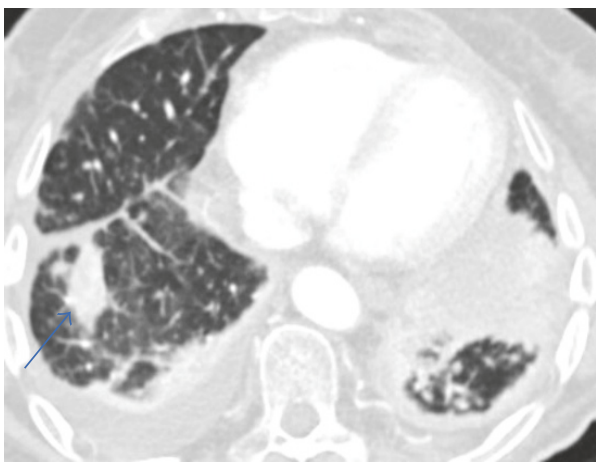

(d)

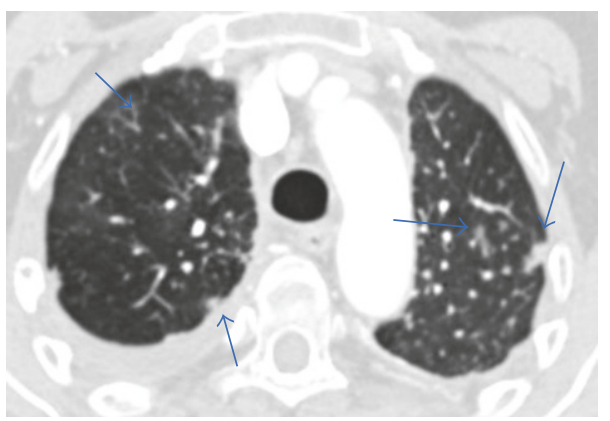

(e)

Figure 12: Chest CT. Multislice chest axial CT-images on mediastinal window (a, b, and c) show increase in size of the main lesion (a) and pleural metastases in the left side (arrows) and in contralateral side (arrowhead); a new lesion in the right lung is observed (arrow in (c)). Multislice chest axial CT-images on lung window ( $\mathrm{d}$ and e) show the new contralateral lesion (arrow in (d)) and the parenchymal pulmonary nodules did not vary significantly in size from the previous studies (arrows in (e)).

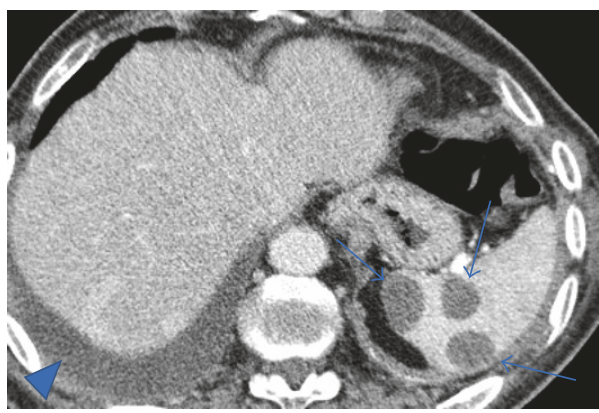

(a)

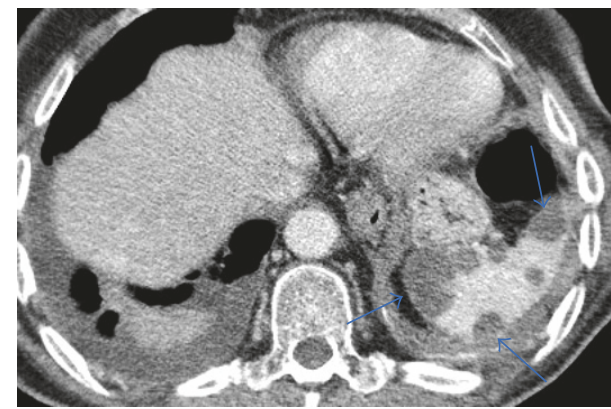

(b)

Figure 13: Multislice chest CT. Axial images on mediastinal window at the pulmonary bases (a and b) show increase in size and number of the nodular spleen lesions (arrows). A pleural effusion in the right side is also apparent (arrowhead). 
Although histologic calcifications are common, radiologic visible calcifications are rare. In long-standing cases or after treatment, extensive calcification of the nodules can be seen $[67,71]$.

PET/CT findings can demonstrate increased FDGuptakes but usually are not a pivotal tool for the diagnosis, and a negative PET cannot exclude $\mathrm{PEH}[72,73]$. This false negative result is thought to be caused because of the small size of nodules, little FDG activity in the neoplasm, or low cellular density. Conversely, other studies show that FDG uptake may reflect the activation of $\mathrm{PEH}$ tumor cells, which is a sign of a poorer prognosis $[74,75]$. One particular study demonstrated the PET/CT scan utility to differentiate $\mathrm{PEH}$ from amyloidosis in a patient with both conditions [73]. Most patients who underwent PET/CT in the study by Woo et al. [32] showed increased FDG uptake at the corresponding lung lesions on CT.

The most problematic pattern, undoubtedly, is the multinodular pattern where the lung nodules were $20 \mathrm{~mm}$ or less in diameter, decreasing the diagnostic accuracy and reliability of PET-CT.

Due to its rarity and heterogeneous mode of presentation, diagnosis of PEH can be really defiant. The diagnosis usually requires a lung biopsy, and histopathological samples are usually obtained from open-lung or thoracoscopic biopsy. Chest CT-guided lung biopsy can also be an option due to potential increased risk of bleeding associated with this vascular-like tumor or when the lesion is peripheral. A few reports report diagnosis made through bronchoscopy biopsies $[8,71,76]$. Fine needle aspiration can produce erroneous results [77].

The diagnosis is made on the basis of these histopathological features and confirmed by positive immunohistochemistry staining for vascular-endothelial markers, like CD31, CD34, and factor VIII [46].

Some histologic findings, like spindle tumor cells and fibrinous pleuritic lesion with extrapleural tumor cells proliferation, are linked to a worse prognosis $[27,28,78]$. Regarding correlation between the histopathological findings and prognosis Kitaichi et al. [27] found that fibrinofibrous pleuritic lesions with extrapleural proliferation of tumor cells and the presence of spindle tumor cells were the characteristics associated with worse prognosis. Interestingly, intravascular invasion and invasion of the visceral pleura by tumor cells without fibrinous pleuritis were observed in the two patients with spontaneous partial regression in their study.

In a more recent study, Anderson et al. [14], in 39 cases of $\mathrm{EH}$ with thoracic involvement, found that higher tumor grade and the presence of pleural involvement in lung and/or pleural tumors correlate with poor prognosis. They suggest that the reported criteria for classifying and grading malignant vascular tumors within soft tissue might be applicable to tumors in the thoracic cavity, including PEH.

There is no established standard treatment consensus for therapeutic regimens available, particularly owing to its borderline malignancy features and scarcity of cases [30, 79]. Spontaneous partial regressions are reported, particularly in asymptomatic patients, as we already reported [27]. Radiotherapy has proven to be ineffective for $\mathrm{PEH}$ because of the tumor's radiobiological characteristics, particularly the slow growth of tumor cells [37]. Surgery when tumor resection is feasible is usually considered the treatment of choice [80, 81]. However, a complete surgical resection is usually not feasible. Chemotherapy/immunostimulants in patients with disseminated disease and lung transplantation can also be an option $[28,58,59,61,81-85]$. Although there are a small number of reports about the effectiveness of chemotherapy, a general standard of chemotherapy is usually accepted for PEH [8]. Pinet et al. [82] reported a case of an aggressive form of pleural $\mathrm{EH}$ resulting in complete remission after treatment with carboplatin plus etoposide. Given the vascular origin of this tumor, the use of antiangiogenetic drugs reasonably might achieve good outcomes, including thalidomide, lenalidomide, and bevacizumab [61, 79, 84-86]. Ye et al. [58], in their review concerning chemotherapy and immunotherapy used in $\mathrm{PEH}$, demonstrated a good partial response to chemotherapy with carboplatin, paclitaxel, bevacizumab, thalidomide, and $\alpha$-interferon. In their study, these authors also described three patients with stabilization of the disease and a dramatic improvement in clinical status when treated with a combination regimen that included Endostar $^{\circledR}$ or bevacizumab. This was the first report of the efficacy of Endostar, a recently introduced recombinant human endostatin, considered to be a valuable antiangiogenic agent. However, no change in the size of the pulmonary nodules over the period of chemotherapy was observed and treatment was unable to stop the progression of disease. Further studies of treatment are warranted to provide a better knowledge for different combination chemotherapies options to treat PEH.

Regular follow-up with no active therapy has been employed in asymptomatic patients, specifically in cases with diffuse lesions corresponding to multinodular pattern $[2,74$, 87].

\section{Conclusions}

These two cases emphasise the large spectrum of presentation, clinical behaviour, and outcome of PHE.

Further investigations are essential to elucidate the progression of the disease and therapeutic options for patients with $\mathrm{PEH}$.

Particularly, different imaging patterns of PHE need to be correlated with the recent molecular/genetic features identified, in order to confirm their prognostic value.

\section{Conflicts of Interest}

The authors declare that there are no conflicts of interest regarding the publication of this paper.

\section{References}

[1] S. W. Weiss, K. G. Ishak, D. H. Dail, D. E. Sweet, and F. M. Enzinger, "Epithelioid hemangioendothelioma and related lesions," Semin Diagn Pathol, vol. 3, no. 4, pp. 259-287, 1986, http://www.ncbi.nlm.nih.gov/pubmed/3303234. 
[2] D. H. Dail, A. A. Liebow, J. T. Gmelich et al., "Intravascular, bronchiolar, and alveolar tumor of the lung (IVBAT): An analysis of twenty cases of a peculiar sclerosing endothelial tumor," Cancer, vol. 51, no. 3, pp. 452-464, 1983.

[3] de Albuquerque A. K. A. C., S. d. O. Romano, and A. L. A. Eisenberg, "Epithelioid hemangioendothelioma: 15 years at the National Cancer Institute. Literature review," Brazilian Journal of Pathology and Laboratory Medicine, vol. 49, no. 2, pp. 119-125, 2013, http://www.scielo.br/scielo.php?script=sci_ arttext\&amp;pid=S1676-24442013000200007.

[4] C. D. M. Fletcher, J. A. Bridge, and M. F. Hogendoorn PCW, WHO Classification of Tumours of Soft Tissue and Bone, vol. 5, WHO/IARC Classification of Tumours, 4th edition, 2013, http://publications.iarc.fr/Book-And-Report-Series/Who-IarcClassification-Of-Tumours/Who-Classification-Of-TumoursOf-Soft-Tissue-And-Bone-2013.

[5] B. Corrin, B. Manners, M. Millard, and L. Weaver, "Histogenesis of the so-called "intravascular bronchioloalveolar tumour"," The Journal of Pathology, vol. 128, no. 3, pp. 163-167, 1979.

[6] C. M. Weldon-Linne, T. A. Victor, M. L. Christ, and W. A. Fry, "Angiogenic nature of the "intravascular bronchioloalveolar tumor" of the lung: an electron microscopic study," Archives of Pathology \& Laboratory Medicine, vol. 105, no. 4, pp. 174-179, 1981, http://www.ncbi.nlm.nih.gov/pubmed/6260056.

[7] U. Flucke, R. J. C. Vogels, N. de Saint Aubain Somerhausen et al., "Epithelioid Hemangioendothelioma: clinicopathologic, immunhistochemical, and molecular genetic analysis of 39 cases," Diagnostic Pathology, vol. 9, no. 1, p. 131, 2014.

[8] P. Cronin and D. Arenberg, "Pulmonary epithelioid hemangioendothelioma: an unusual case and a review of the literature," Chest, vol. 125, no. 2, pp. 789-792, 2004.

[9] M. Kim, J. Chang, H. Choi et al., "Pulmonary epithelioid hemangioendothelioma misdiagnosed as a benign nodule," World Journal of Surgical Oncology, vol. 13, no. 1, p. 107, 2015.

[10] R. Palfoldi, M. Radacs, and E. Csada, "Pulmonary epithelioid haemangioendothelioma studies in vitro and in vivo: new diagnostic and treatment methods," In Vivo, vol. 27, no. 2, pp. 221-225, 2013.

[11] W. D. Travis, E. Brambilla, A. P. Burke, and N. A. Marx A, WHO Classification of Tumours of the Lung, Pleura, Thymus and Heart, vol. 7, WHO/IARC Classification of Tumours, Accessed, 4th edition, 2015, http://publications.iarc.fr/Book-And-ReportSeries/Who-Iarc-Classification-Of-Tumours/Who-ClassificationOf-Tumours-Of-The-Lung-Pleura-Thymus-And-Heart-2015.

[12] W. D. Travis, E. Brambilla, A. G. Nicholson et al., "The 2015 World Health Organization Classification of Lung Tumors," Journal of Thoracic Oncology, vol. 10, no. 9, pp. 1243-1260, 2015.

[13] C. Errani, L. Zhang, Y. S. Sung et al., "A novel WWTR1CAMTA1 gene fusion is a consistent abnormality in epithelioid hemangioendothelioma of different anatomic sites," Genes Chromosomes and Cancer, vol. 50, no. 8, pp. 644-653, 2011.

[14] T. Anderson, L. Zhang, M. Hameed, V. Rusch, W. D. Travis, and C. R. Antonescu, "Thoracic epithelioid malignant vascular tumors: a clinicopathologic study of 52 cases with emphasis on pathologic grading and molecular studies of WWTR1-CAMTA1 fusions," The American Journal of Surgical Pathology, vol. 39, no. 1, pp. 132-139, 2015.

[15] K. Lau, M. Massad, C. Pollak et al., "Clinical patterns and outcome in epithelioid hemangioendothelioma with or without pulmonary involvement: Insights from an internet registry in the study of a rare cancer," Chest, vol. 140, no. 5, pp. 1312-1318, 2011.
[16] S. Y. Ha, I. H. Choi, J. Han et al., "Pleural epithelioid hemangioendothelioma harboring CAMTA1 rearrangement," Lung Cancer, vol. 83, no. 3, pp. 411-415, 2014.

[17] M. R. Mendlick, M. Nelson, D. Pickering et al., “Translocation $\mathrm{t}(1 ; 3)(\mathrm{p} 36.3 ; \mathrm{q} 25)$ is a nonrandom aberration in epithelioid hemangioendothelioma," American Journal of Surgical Pathology, vol. 25, no. 5, pp. 684-687, 2001.

[18] MR. Tanas, A. Sboner, AM. Oliveira et al., "Identification of a disease-defining gene fusion in epithelioid hemangioendothelioma," Science Translational Medicine, vol. 3, no. 98, p. 98ra82, 2011.

[19] C. R. Antonescu, F. Le Loarer, J.-M. Mosquera et al., "Novel YAP1-TFE3 fusion defines a distinct subset of epithelioid hemangioendothelioma," Genes Chromosomes and Cancer, vol. 52, no. 8, pp. 775-784, 2013.

[20] C. Antonescu, "Malignant vascular tumors-an update," Modern Pathology, vol. 27, S30-S38, 2014.

[21] N. R. Patel, A. A. Salim, H. Sayeed et al., "Molecular characterization of epithelioid haemangioendotheliomas identifies novel WWTR1-CAMTA1 fusion variants," Histopathology, vol. 67, no. 5, pp. 699-708, 2015.

[22] P. E. Mascarelli, J. R. Iredell, R. G. Maggi, G. Weinberg, and E. B. Breitschwerdt, "Bartonella species bacteremia in two patients with epithelioid hemangioendothelioma," Journal of Clinical Microbiology, vol. 49, no. 11, pp. 4006-4012, 2011.

[23] T. Haruki, T. Arai, H. Nakamura, K. Nosaka, K. Shomori, and H. Ito, "Pulmonary Epithelioid Hemangioendothelioma with PlGF Expression: Report of a Case," Thoracic and Cardiovascular Surgeon, vol. 59, no. 2, pp. 128-130, 2011.

[24] N. P. Ohori, S. A. Yousem, E. Sonmez-Alpan, and T. V. Colby, "Estrogen and progesterone receptors in lymphangioleiomyomatosis, epithelioid hemangioendothelioma, and sclerosing hemangioma of the lung," American Journal of Clinical Pathology, vol. 96, no. 4, pp. 529-535, 1991.

[25] M. Mcculloch, M. Russin, and A. Nachat, "Recurrence of epithelioid hemangioendothelioma during pregnancy: case report and systematic review," The Permanente Journal, vol. 20, no. 3, pp. 84-89, 2016.

[26] R. M. S. Amin, K. Hiroshima, T. Kokubo et al., "Risk factors and independent predictors of survival in patients with pulmonary epithelioid haemangioendothelioma. Review of the literature and a case report," Respirology, vol. 11, no. 6, pp. 818-825, 2006.

[27] M. Kitaichi, S. Nagai, K. Nishimura et al., "Pulmonary epithelioid haemangioendothelioma in 21 patients, including three with partial spontaneous regression," European Respiratory Journal, vol. 12, no. 1, pp. 89-96, 1998.

[28] P. Bagan, M. Hassan, F. L. P. Barthes et al., "Prognostic factors and surgical indications of pulmonary epithelioid hemangioendothelioma: a review of the literature," The Annals of Thoracic Surgery, vol. 82, no. 6, pp. 2010-2013, 2006.

[29] J. Shao and J. Zhang, "Clinicopathological characteristics of pulmonary epithelioid hemangioendothelioma: A report of four cases and review of the literature," Oncology Letters, vol. 8, no. 6, pp. 2517-2522, 2014.

[30] A. Sardaro, L. Bardoscia, M. F. Petruzzelli, and M. Portaluri, "Epithelioid hemangioendothelioma: an overview and update on a rare vascular tumor," Oncol Rev, vol. 8, no. 2, p. 259, 2014.

[31] J. Salijevska, R. Watson, A. Clifford, A. I. Ritchie, F. Mauri, and D. Adeboyeku, "Pleural epithelioid hemangioendothelioma: literature summary and novel case report," Journal of Clinical Medicine Research, vol. 7, no. 7, pp. 566-570, 2015. 
[32] J. H. Woo, T. J. Kim, K. S. Lee, T. S. Kim, and B.-T. Kim, "Epithelioid hemangioendothelioma in the thorax: Clinicopathologic, CT, PET, and prognostic features," Medicine (United States), vol. 95, no. 30, article no. 2010, 2016.

[33] S. Reich, H. Ringe, B. Uhlenberg, B. Fischer, and V. Varnholt, "Epithelioid hemangioendothelioma of the lung presenting with pneumonia and heart rhythm disturbances in a teenage girl," Journal of Pediatric Hematology/Oncology, vol. 32, no. 4, pp. 274-276, 2010.

[34] S. K. Teo, S. C. Chiang, and K. K. Tan, "Intravascular bronchioloalveolar tumour. A 20-year survival," The Medical Journal of Australia, vol. 142, no. 3, pp. 220-222, 1985, http://www.ncbi.nlm.nih.gov/pubmed/3969042.

[35] B. K. Bollinger, W. B. Laskin, and C. B. Knight, "Epithelioid hemangioendothelioma with multiple site involvement. Literature review and observations," Cancer, vol. 73, no. 3, pp. 610-615, 1994.

[36] J. F. Tomashefski, D. H. Dail, and Dail D. H., Dail and Hammar's Pulmonary Pathology, Springer, 2008.

[37] M. E. van Kasteren, A. A. van der Wurff, F. M. Palmen, A. Dolman, and J. F. Miseré, "Epithelioid haemangioendothelioma of the lung: clinical and pathological pitfalls," The European Respiratory Journal, vol. 8, no. 9, pp. 1616-1619, 1995, http://www.ncbi.nlm.nih.gov/pubmed/8575593.

[38] H. Yanagawa, Y. Hashimoto, H. Bando, Y. Takishita, and T. Nagano, "Intravascular bronchioloalveolar tumor with skin metastases," Chest, vol. 105, no. 6, pp. 1882-1884, 1994.

[39] S. R. Mehta, A. Das, N. Barnard, and A. Marcus, "Metastatic Pulmonary Epithelioid Hemangioendothelioma: A case report and review of the literature," Respiratory Medicine Case Reports, vol. 7, no. 1, pp. 17-20, 2012.

[40] H.-S. Ro, J. Y. Shin, S.-G. Roh, N.-H. Lee, K.-M. Yang, and W.S. Moon, "A rare case of pulmonary epithelioid hemangioendothelioma presenting with skin metastasis," Archives of Plastic Surgery, vol. 43, no. 3, pp. 284-287, 2016.

[41] B. de Singly, E. Pommaret, F. Sailhan, and R. Coriat, "Colonic mestastasis of an epithelioid hemangioendothelioma: An unusual cause of periumbilical pain and weight loss," Digestive and Liver Disease, vol. 43, no. 5, p. e10, 2011.

[42] E. S. Yi, W. R. Auger, P. J. Friedman, T. A. Morris, and S. S. Shin, "Intravascular bronchioloalveolar tumor of the lung presenting as pulmonary thromboembolic disease and pulmonary hypertension," Archives of Pathology \& Laboratory Medicine, vol. 119, no. 3, pp. 255-260, 1995, http://www.ncbi.nlm.nih.gov/ pubmed/7534058.

[43] L. Yu, T. Gu, Z. Xiu, E. Shi, and X. Zhao, "Primary pleural epithelioid hemangioendothelioma compressing the myocardium," Journal of Cardiac Surgery, vol. 28, no. 3, pp. 266-268, 2013.

[44] S. Suster, C. A. Moran, and M. N. Koss, "Epithelioid hemangioendothelioma of the anterior mediastinum. Clinicopathologic, immunohistochemical, and ultrastructural analysis of 12 cases," The American Journal of Surgical Pathology, vol. 18, no. 9, pp. 871-881, 1994, http://www.ncbi.nlm.nih.gov/pubmed/ 8067508.

[45] D. Márquez-Medina, J. C. Samamé-Pérez-Vargas, N. TusetDerAbrain, A. Montero-Fernández, T. Taberner-Bonastre, and J. M. Porcel, "Pleural epithelioid hemangioendothelioma in an elderly patient. A case report and review of the literature," Lung Cancer, vol. 73, no. 1, pp. 116-119, 2011.

[46] E. Y. Kim, T. S. Kim, J. Han, J. Y. Choi, O. J. Kwon, and J. Kim, "Thoracic epithelioid hemangioendothelioma: Imaging and pathologic features," Acta Radiologica, vol. 52, no. 2, pp. 161$166,2011$.

[47] N. Sakamoto, S. Adachi, S. Monzawa et al., "High resolution CT findings of pulmonary epithelioid hemangioendothelioma: Unusual manifestations in 2 cases," Journal of Thoracic Imaging, vol. 20, no. 3, pp. 236-238, 2005.

[48] P. Luburich, M. C. Ayuso, C. Picado, J. Serra-Batlles, J. F. Ramirez, and M. Sole, "CT of pulmonary epithelioid hemangioendothelioma," Journal of Computer Assisted Tomography, vol. 18, no. 4, pp. 562-565, 1994, http://www.ncbi.nlm.nih.gov/ pubmed/8040439.

[49] K. Liu, P. Xie, W. Peng, and Z. Zhou, "The computed tomographic findings of pulmonary epithelioid hemangioendothelioma," Radiologia Medica, vol. 119, no. 9, pp. 705-713, 2014.

[50] G. T. Noh, K. J. Lee, H. J. Sohn, K. H. Lee, W. S. Heo, and B. S. Koh, "Pulmonary epithelioid hemangioendothelioma misconceived as pulmonary metastasis of other malignancies," Yeungnam University Journal of Medicine, vol. 33, no. 1, pp. 7275, 2016.

[51] M. J. Ledson, R. Convery, A. Carty, and C. C. Evans, "Epithelioid haemangioendothelioma," Thorax, vol. 54, no. 6, pp. 560-561, 1999.

[52] J. J. Erasmus, H. P. McAdams, and M. S. Carraway, "A 63-yearold woman with weight loss and multiple lung nodules," Chest, vol. 111, no. 1, pp. 236-238, 1997.

[53] C. Roudier-Pujol, O. Enjolras, J. Lacronique et al., "Multifocal epithelioid hemangioendothelioma with partial remission after interferon alfa-2a treatment," Ann Dermatol Venereol, vol. 121, no. 12, pp. 898-904, 1994, http://www.ncbi.nlm.nih.gov/ pubmed/7632008.

[54] M. Miettinen, Y. Collan, P. Halttunen, T. Maamies, and P. Vilkko, "Intravascular bronchioloalveolar tumor," Cancer, vol. 60, no. 10, pp. 2471-2475, 1987.

[55] R. Rojas-Vigott, C. M. Castro, and S. R. Méndez, "P2.24: pulmonary-epithelioid hemangioendothelioma: a case report of spontaneous regression," Journal of Thoracic Oncology, vol. 11, S231-S232, no. 10, 2016.

[56] V. Semenisty, I. Naroditsky, Z. Keidar, and G. BarSela, "Pazopanib for metastatic pulmonary epithelioid hemangioendothelioma-a suitable treatment option: Case report and review of anti-angiogenic treatment options," $B M C$ Cancer, vol. 15, no. 1, article no. 402, 2015.

[57] S. Mirza, A. Glucksman, and J. McArdle, "Pulmonary epithelioid hemangioendothelioma: one cause of nodular parenchymal lung disease," Chest, vol. 148, no. 4, pp. 572A-572B, 2015.

[58] B. Ye, W. Li, J. Feng, J.-X. Shi, Y. Chen, and B.-H. Han, "Treatment of pulmonary epithelioid hemangioendothelioma with combination chemotherapy: Report of three cases and review of the literature," Oncology Letters, vol. 5, no. 5, pp. 14911496, 2013.

[59] E. Radzikowska, E. Szczepulska-Wójcik, M. Chabowski, K. Oniszh, R. Langfort, and K. Roszkowski, "Pulmonary epithelioid haemangioendothelioma-interferon 2-alpha treatment-case report," Pneumonologia i Alergologia Polska, vol. 76, no. 4, pp. 281-285, 2008, http://www.ncbi.nlm.nih.gov/ pubmed/18785134.

[60] S. Saleiro, M. Barbosa, C. Souto Moura, J. Almeida, and S. Ferreira, "Epithelioid hemangioendothelioma - a rare pulmonary tumor," Revista Portuguesa de Pneumologia, vol. 14, no. 3, pp. 421-425, 2017, http://www.ncbi.nlm.nih.gov/pubmed/ 18528603. 
[61] S. Gaur, A. Torabi, and T. J. O’Neill, "Activity of angiogenesis inhibitors in metastatic epithelioid hemangioendothelioma: a case report," Cancer Biology \& Medicine, vol. 9, no. 2, pp. 133136, 2012.

[62] M. I. Ebright, M. F. Zakowski, J. Martin et al., "Clinical pattern and pathologic stage but not histologic features predict outcome for bronchioloalveolar carcinoma," Ann Thorac Surg, vol. 74, no. 5, pp. 1640-1646-1647, 2002, http://www.ncbi.nlm.nih.gov/ pubmed/12440623.

[63] G. Mukundan, B. A. Urban, F. B. Askin, and E. K. Fishman, "Pulmonary epithelioid hemangioendothelioma: Atypical radiologic findings of a rare tumor with pathologic correlation," Journal of Computer Assisted Tomography, vol. 24, no. 5, pp. 719$720,2000$.

[64] G. J. Ross, L. Violi, A. C. Friedman, P. R. Edmonds, and E. Unger, "Intravascular bronchioloalveolar tumor: CT and pathologic correlation," Journal of Computer Assisted Tomography, vol. 13, no. 2, pp. 240-243, http://www.ncbi.nlm.nih.gov/pubmed/ 2647795.

[65] A. Bahrami, T. C. Allen, and P. T. Cagle, "Pulmonary epithelioid hemangioendothelioma mimicking mesothelioma," Pathology International, vol. 58, no. 11, pp. 730-734, 2008.

[66] E. J. Crotty, H. P. McAdams, J. J. Erasmus, T. A. Sporn, and V. L. Roggli, "Epithelioid hemangioendothelioma of the pleura: Clinical and radiologic features," American Journal of Roentgenology, vol. 175, no. 6, pp. 1545-1549, 2000.

[67] X. Jinghong and C. Lirong, "Pulmonary epithelioid hemangioendothelioma accompanied by bilateral multiple calcified nodules in lung," Diagnostic Pathology, vol. 6, no. 1, article no. 21, 2011.

[68] R. P. Kumar, D. A. Smith, C. J. Hilton, and D. V. Parums, "A case of epithelioid haemangioendothelioma (EHE) of the lung with bronchial brushing cytology," Cytopathology, vol. 10, no. 2, pp. 132-136, 1999.

[69] J. H. Kim, E. B. Lee, S. Kim et al., "A case of hypertrophic osteoarthropathy associated with epithelioid hemangioendothelioma," Journal of Korean Medical Science, vol. 19, no. 3, pp. 484-486, 2004.

[70] K. Fagen, E. D. Silverman, and Cole R. L., "Detection of a pulmonary epithelioid hemangioendothelioma by FDG PET scan," Clinical Nuclear Medicine, vol. 29, no. 11, pp. 758-759, 2004, http://www.ncbi.nlm.nih.gov/pubmed/15483505.

[71] D. Rosengarten, M. R. Kramer, G. Amir, L. Fuks, and N. Berkman, "Pulmonary epithelioid hemangioendothelioma," The Israel Medical Association Journal, vol. 13, no. 11, pp. 676-679, 2011.

[72] R. Cazzuffi, N. Calia, F. Ravenna et al., "Primary pulmonary epithelioid hemangioendothelioma: a rare cause of pet-negative pulmonary nodules," Case Reports in Medicine, vol. 2011, Article ID 262674, 2011.

[73] L. Yi, D. Cheng, H. Shi et al., "Pulmonary epithelioid hemangioendothelioma coexisting with pulmonary nodular amyloidosis: Case discussion and review of the literature," International Journal of Clinical and Experimental Medicine, vol. 7, no. 7, pp. 1891-1897, 2014.

[74] K. Okamura, T. Ohshima, R. Nakano, H. Ouchi, K. Takayama, and Y. Nakanishi, "A case of pulmonary epithelioid hemangioendothelioma surviving 10 years without treatment," Annals of Thoracic and Cardiovascular Surgery, vol. 16, no. 6, pp. 432435, 2010.
[75] S. Watanabe, F. Yano, T. Kita et al., "18F-FDG-PET/CT as an indicator for resection of pulmonary epithelioid hemangioendothelioma," Annals of Nuclear Medicine, vol. 22, no. 6, pp. 521524, 2008.

[76] K. K. Sakata, M. B. Gotway, M. L. Smith et al., "Pulmonary epithelioid hemangioendothelioma diagnosed with endobronchial biopsies: A case report and literature review," Journal of Bronchology and Interventional Pulmonology, vol. 23, no. 2, pp. 168-173, 2016.

[77] H. S. Ryu, S.-S. Lee, H.-S. Choi, H. Baek, and J. S. Koh, "A case of pulmonary malignant epithelioid hemangioendothelioma misdiagnosed as adenocarcinoma by fine needle aspiration cytology," Diagnostic Cytopathology, vol. 39, no. 11, pp. 801-807, 2011.

[78] T. Schattenberg, R. Kam, M. Klopp et al., "Pulmonary epithelioid hemangioendothelioma: Report of three cases," Surgery Today, vol. 38, no. 9, pp. 844-849, 2008.

[79] L. B. Angela Sardaro, M. F. Petruzzelli, and B. D. Maurizio Portaluri, "Pulmonary epithelioid hemangioendothelioma: advances in treatment options despite a rare vascular tumor," Chemother Open Access, vol. 4, no. 3, pp. 2014-2015, 2014.

[80] K. Eguchi and M. Sawafuji, "Surgical management of a patient with bilateral multiple pulmonary epithelioid hemangioendothelioma: report of a case," Surgery Today, vol. 45, no. 7, pp. 904-906, 2014.

[81] Y. Mizuno, H. Iwata, K. Shirahashi, Y. Hirose, and H. Takemura, "Pulmonary epithelioid hemangioendothelioma," General Thoracic and Cardiovascular Surgery, vol. 59, no. 4, pp. 297-300, 2011.

[82] C. Pinet, A. Magnan, L. Garbe, M.-J. Payan, and D. Vervloet, "Aggressive form of pleural epithelioid haemangioendothelioma: Complete response after chemotherapy," European Respiratory Journal, vol. 14, no. 1, pp. 237-238, 1999.

[83] N. Desie, D. E. Van Raemdonck, L. J. Ceulemans et al., "Combined or serial liver and lung transplantation for epithelioid hemangioendothelioma: A case series," American Journal of Transplantation, vol. 15, no. 12, pp. 3247-3254, 2015.

[84] A. Mizota, K. Shitara, and T. Fukui, "Bevacizumab chemotherapy for pulmonary epithelioid hemangioendothelioma with severe dyspnea," Journal of Thoracic Oncology, vol. 6, no. 3, pp. 651-652, 2011.

[85] L. Belmont, L. Zemoura, and L. J. Couderc, "Pulmonary epithelioid haemangioendothelioma and bevacizumab," Journal of Thoracic Oncology, vol. 3, no. 5, pp. 557-558, 2008.

[86] Y. H. Kim, M. Mishima, and A. Miyagawa-Hayashino, "Treatment of pulmonary epithelioid hemangioendothelioma with bevacizumab," Journal of Thoracic Oncology, vol. 5, no. 7, pp. 1107-1108, 2010.

[87] A. Haro, G. Saitoh, S. Tamiya, and A. Nagashima, "Four-year natural clinical course of pulmonary epithelioid hemangioendothelioma without therapy," Thoracic Cancer, vol. 6, no. 4, pp. 544-547, 2015. 


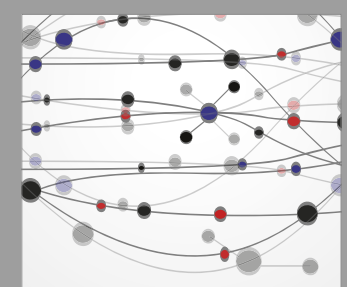

The Scientific World Journal
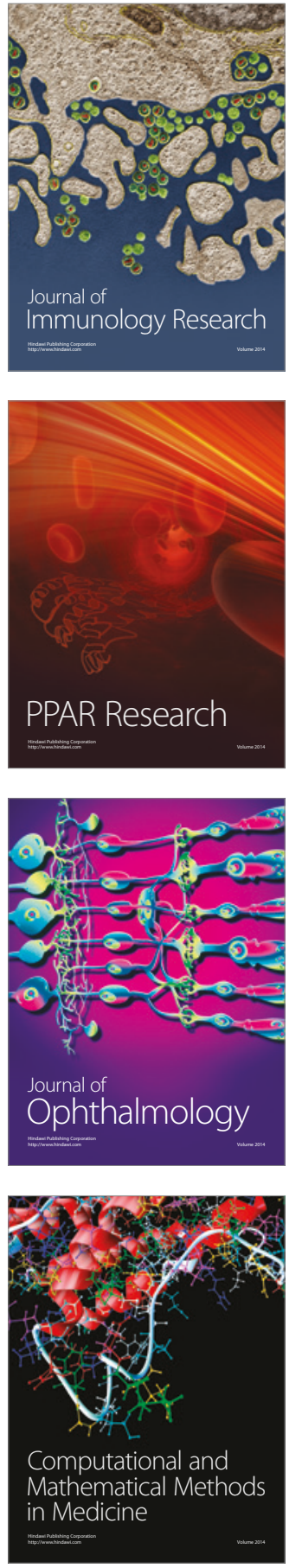

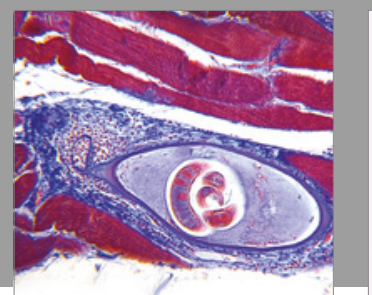

Gastroenterology Research and Practice
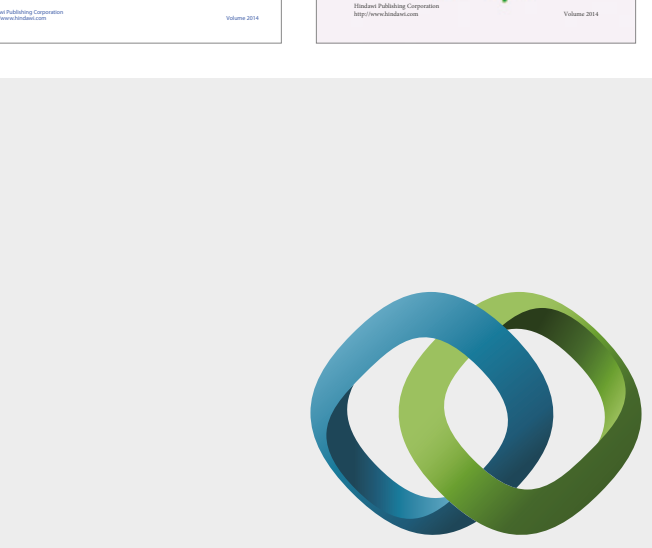

\section{Hindawi}

Submit your manuscripts at

https://www.hindawi.com
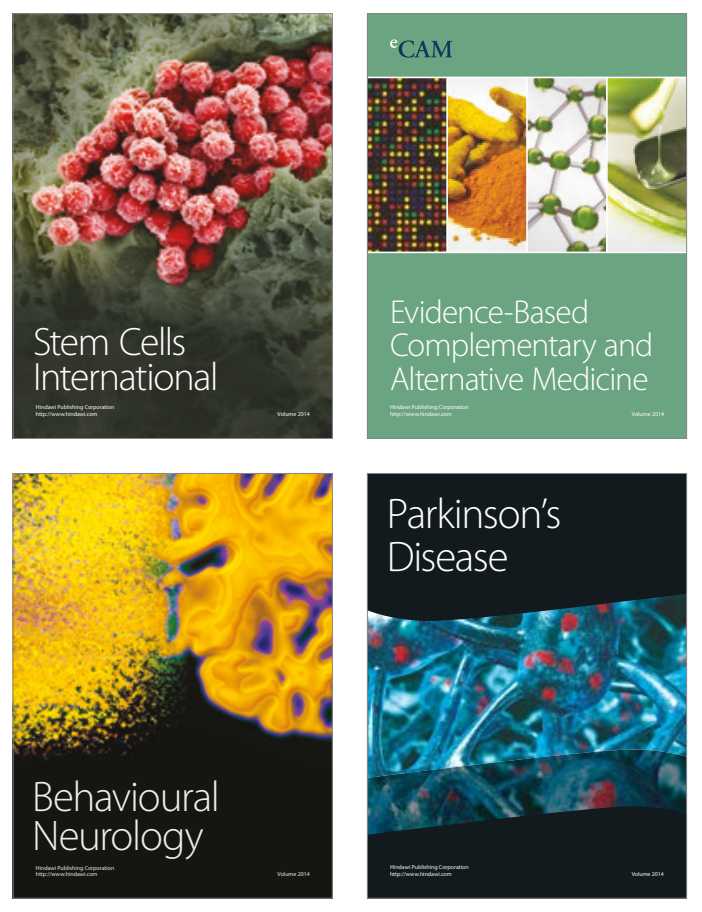
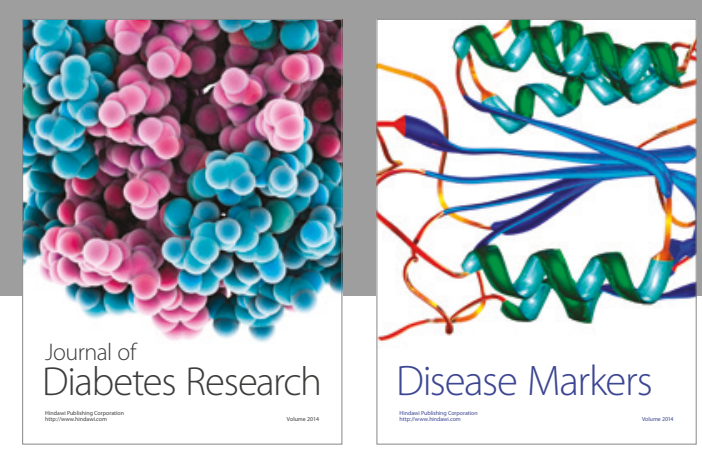

Disease Markers
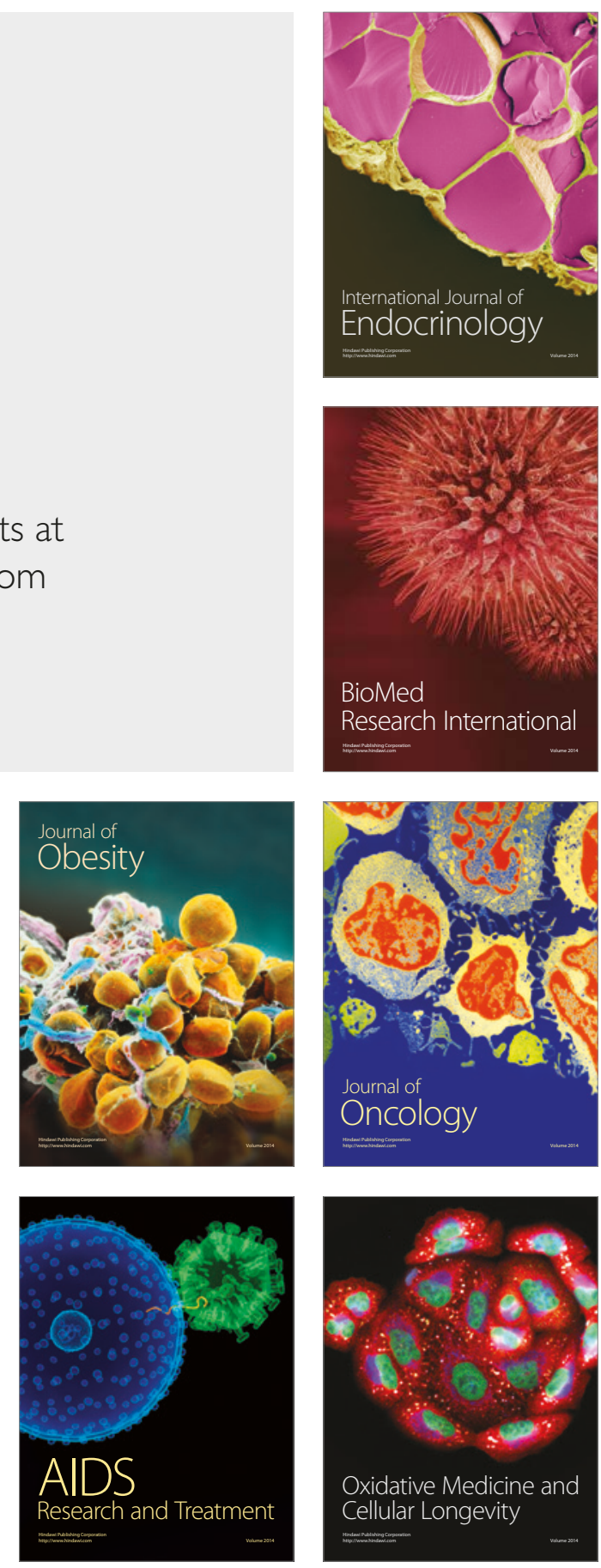